\title{
Dental enamel, fluorosis and amoxicillin
}

\author{
Smalto dentale, fluorosi ed amoxi cillina
}

I. Ciarrocchi, ${ }^{1}$ C. Masci, ${ }^{1}$ A. Spadaro, ${ }^{2}$ G. Caramia,${ }^{3}$ A. Monaco ${ }^{1}$

Key words: Amoxicillin, Dental Fluorosis, Dental Enamel, MIH

\section{Riassunto}

Introduzione: L'amoxicillina è uno degli antibiotici più utilizzati in età pediatrica per il trattamento delle infezioni dell'alto tratto respiratorio ed in modo particolare per il trattamento dell'otite media, patologia frequente nella prima e seconda infanzia. Da alcuni studi emerge che l'utilizzo di amoxicillina durante i primi anni di vita potrebbe essere associato ad una particolare forma di fluorosi dentale le cui lesioni si localizzano principalmente a livello dei primi molari permanenti e, seppure meno frequentemente a livello degli incisivi. Gli effetti dell'amoxicillina sembrano essere indipendenti da altri fattori di rischio come assunzione di fluoro, prematurità alla nascita, ipossia, ipocalcemia, esposizione alla diossina, varicella, otite media, febbre alta e potrebbero avere un impatto significativo sulla salute orale per l'ampio uso di questo farmaco in questo periodo della vita.

Obiettivo: Lo scopo del nostro studio era quello di revisionare l'attuale letteratura riguardo l'associazione tra amoxicillina e fluorosi.

Metodi e Risultati: E' stata effettuata una revisione della letteratura nei database PubMed e Cochrane usando le seguenti parole chiave: amoxicillin*, dental fluorosis*, dental enamel* e $\mathrm{MIH}^{*}$. Dopo aver selezionato gli studi sono stati inclusi nel-

DDS, Department of Paediatric Dentistry, School of Dentistry, University of L'Aquila, Italy

2 DDS, PhD, Department of Paediatric Dentistry, School of Dentistry, University of L'Aquila, Italy

3 MD, Emeritus Head Neonatology and Pediatric Department, Specialized Pediatric Hospital "G. Salesi", Ancona, Italy.

Indirizzo per la corrispondenza (Corresponding author):

Irma Ciarrocchi

University of L'Aquila, School of Dentistry, Department of Paediatric dentistry

Via Vetoio, Coppito, 67100 L'Aquila - Italy

phone: 0862434973 - Email: irma.ciarrocchi@hotmail.it la revisione solo tre articoli rilevanti, pubblicati tra il 1966 e il 2011.

Conclusione: La presenza di numerosi problemi metodologici non ci permette di trarre conclusioni basate su evidenza scientifica. Sono necessari ulteriori studi per stabilire un'eventuale relazione tra amoxicillina e fluorosi. Sulla base dei dati attuali potrebbe essere comunque considerato un atteggiamento prudente quello di limitare la prescrizione di questo farmaco per infezioni ricorrenti delle alte vie respiratorie, specialmente per l'otite media, durante i primi due anni di vita, somministrando quando è possibile trattamenti antibiotici alternativi.
Abstract
Introduction: Amoxicillin is one of the most used antibi- otics among pediatric patients for the treatment of upper respiratory tract infections and specially for acute otitis media (AOM), a common diseases of infants and child- hood. It has been speculated that the use of amoxicillin dur- ing early childhood could be associated with dental enamel fluorosis, also described in literature with the term Molar Incisor Hypomineralization (MIH), because they are gener- ally situated in one or more $1^{\text {st }}$ permanent molars and less frequently in the incisors. The effect of Amoxicillin seems to be independent of other risk factors such as fluoride intake, prematurity, hypoxia, hypocalcaemia, exposure to dioxins, chikenpox, otitis media, high fever and could have a signifi- cant impact on oral health for the wide use of this drug in that period of life.
Objective: The aim of this work was to review the current literature about the association between amoxicillin and flu- orosis.
Methods and Results: A literature survey was done by applying the Medline database (Entrez PubMed); the Cochrane Library database of the Cochrane Collaboration 
(CENTRAL). The databases were searched using the following strategy and keywords: amoxicillin* AND (dental fluorosis* OR dental enamel*) AND MIH*. After selecting the studies, only three relevant articles published between 1966 and 2011 were included in the review.

Conclusion: The presence of several methodological issues does not allow to draw any evidence-based conclusions. No evidence of association was detected, therefore, there is a need of further well-designed studies to assess the scientific evidence of the relationship between amoxicillin and fluorosis and to restrict the prescription of this drug for recurrent upper respiratory tract infections especially acute otitis media (AOM) during the first two years of life. When it is possible can be opportune to use an alternative antibiotic treatment.

\section{Introduction}

Dental enamel formation is a complex process involving cellular proliferation and differentiation through the sequential epithelial-mesenchymal interaction, secretion of the tissuespecific matrix proteins, transport of the ions including calcium and fluoride, and precipitation and alignment of enamel crystals through the multiple interactions between organic and inorganic molecules. ${ }^{1}$

The amelogenesis is therefore a delicate process, and sensitive to the action of various external agents that may cause a change to the environment in which the ameloblasts are functioning, putatively contributing to the development of defective enamel. 2

There are many and unclear causal factors for this condition. According to Arrow ${ }^{3}$ and Crombie 2 prematurity, medical care in the neonatal period and other health conditions immediately following birth were significant risk factors in the occurrence of enamel defects. Hypoxia, hypocalcaemia, exposure to "dioxins", ${ }^{4}$ chikenpox occuring around the third year of life, 5 otitis media and high fever too ${ }^{6}$ has been implicated in the occurence of enamel defects.

In addition to the above factors, ${ }^{2-6}$ has been reported that dental fluorosis mainly results from exposure to excessive fluoride during enamel formation. ${ }^{7}$ However, the risk of developing dental fluorosis in permanent teeeth is limited to children aged less 9 years, because enamel, from that moment, is not more susceptible, since pre-eruptive enamel maturations of all the teeth, except the third molar, is completed. ${ }^{8}$ The safety threshold beyond that the risk of fluorosis increased should be considered $0.05-0.07 \mathrm{mg}$ fluoride/ $\mathrm{kg}$ body weight/day.9,10 Therefore the evaluation of the amount of fluoride in water and foods is necessary to avoid an overdose (TABLE 1).

Fluorosis occurs when fluoride interacts with mineralizing tissues, causing alterations in the mineralization process. In den- tal enamel, fluorosis causes subsurface hypomineralizations or porosity, which extends toward the dentinal-enamel junction as severity increases. ${ }^{11}$ These enamel defects have different severity and are usually asymmetric, with well demarcated white/opaque, yellow or brown discoloration ${ }^{12}$ that resemble the direction of the natural incremental lines of enamel formation. In literature these enamel defects are described with

\begin{tabular}{|c|c|}
\hline \multicolumn{2}{|c|}{$\begin{array}{l}\text { CONTENT OF FLUORIDE (MG/L OF FLUORIDE IONS) } \\
\text { IN SOME ITALIAN MINERAL WATERS (ASCENDING ORDER). }\end{array}$} \\
\hline TRADE NAME & FLUORIDE (mg/L) \\
\hline Vera & Absent \\
\hline San Benedetto & Sign \\
\hline Gaia & Sign \\
\hline Rocchetta & Sign \\
\hline Fiuggi & Sign \\
\hline Panna & $0,05-0,06$ \\
\hline Aqua & 0,08 \\
\hline Paravita & 0,10 \\
\hline Lete & 0,10 \\
\hline Tinnea & 0,16 \\
\hline Sovrana Feja & 0,17 \\
\hline Tesorino & 0,19 \\
\hline Faito & 0,20 \\
\hline Acetosella & 0,22 \\
\hline Sangemini & 0,26 \\
\hline S. Carlo Spinone & 0,28 \\
\hline Levissima & 0,30 \\
\hline Flaminia Nocera Umbra & 0,35 \\
\hline Levico Terme & 0,40 \\
\hline Fonte di Palme & 0,40 \\
\hline Petra Pertusa & 0,40 \\
\hline Fonte Chiara & 0,42 \\
\hline Argentina & 0,44 \\
\hline Boario Terme & 0,45 \\
\hline Traficante & 0,50 \\
\hline S. Andrea & 0,57 \\
\hline Antica Fonte Boario & 0,58 \\
\hline S. Elena Chianciano & 0,60 \\
\hline Acqua della Madonna & 0,60 \\
\hline Italia & 0,60 \\
\hline Ferrarelle & 0,70 \\
\hline Toka & 0,70 \\
\hline Fausta Boario & 0,70 \\
\hline S. Pellegrino & 0,70 \\
\hline Idrea & 0,72 \\
\hline Irno & 0,73 \\
\hline Monticchio & 0,80 \\
\hline Maxima & 0,83 \\
\hline Capannelle & 0,86 \\
\hline Regina & 0,92 \\
\hline Sant'Agata & 0,99 \\
\hline Acqua Sacra & 1,00 \\
\hline Appia & 1,20 \\
\hline Uliveto & 1,40 \\
\hline Montecatini Terme & 1,40 \\
\hline Egeria & 1,60 \\
\hline S. Lucia & 1,65 \\
\hline Fonte Lidia & 1,85 \\
\hline Fucoli & 1,90 \\
\hline Acqua di Nepi & 1,90 \\
\hline S. Acqua Chianciano & 2,00 \\
\hline Claudia & 2,10 \\
\hline S. Paolo & 2,40 \\
\hline
\end{tabular}


the term Molar Incisor Hypomineralization (MIH), because they are generally situated in one or more $1^{\text {st }}$ permanent molars and less frequently in the incisors. ${ }^{13} \mathrm{MIH}$ significantly increase dental treatment need as the teeth are more susceptible to plaque accumulation and dental caries. Consequently MIH poses a significant problem for both the patients and the clinicians, because the affected teeth have significant tissue loss, are often hypersensitive and are difficult to restore, ${ }^{14}$ even if enamel matrix derivative has been recently introduced. ${ }^{15}$ Amoxicillin is one of the most antibiotics used among pediatric patients, for the treatment of upper respiratory tract infections and especially for acute otitis media (AOM), a common diseases of infants and childhood, affecting more than $80 \%$ of children at last once before 3 years of age and which requires adequate therapy. ${ }^{16-18}$ It has been speculated that amoxicillin use during early childhood could be associated with dental enamel defects.7,19 This could have a significant impact on oral dental health for the widespread use of amoxicillin during infant and childhood.

\section{Methods and results}

To identify all the studies that examined the relationship between amoxicillin use and enamel defects in children, a literature search by Medline online database (Entrez PubMed) and the Cochrane Library database of the Cochrane Collaboration (CENTRAL) was performed to assess the scientific evidence of this association. The survey covered the period from 1966 to March 2011. The databases were searched using the following strategy and keywords: amoxicillin* AND (dental fluorosis* OR dental enamel*) AND MIH*.

In our opinion among several paper there are three relevant articles that link amoxicillin use and dental fluorosis.7,20,21

A prospective study of Hong et al.7 evaluated the possible association between the early use of amoxicillin and dental fluorosis during childhood, concluding that there is a significantly elevated risk for dental fluorosis on both permanent first molars and maxillary central incisors and these effects of amoxicillin use were independent of other risk factors, such as fluoride intake and AOM. The authors examined this relationship in early-erupting permanent teeth of 1390 subjects recruited at birth in Iowa hospital in 1992-1995. Parents of recruited children were mailed questionnaires at 3 to 4 month intervals during the subjects' first 32 months of life. Parents were asked to identify specific antibiotics given during each reporting period, including the route and duration of administration. Data were also collected on fluoride intake, illness and breastfeeding.

At approximately nine years of age, 579 partecipants were evaluated for fluorosis of early-erupting permanent teeth using the Fluorosis Risk Index (FRI) by two trained and calibrated examiners, blinded to early exposure history. The sub- jects having FRI definitive to severe fluorosis on both maxillary central incisors were defined case, while control subjects had fluorosis on neither of these incisors. The results showed that by 12 months, $75 \%$ of subjects reported amoxicillin use; by 32 months this percentage increased to $91 \%$. Furthermore at the examination $24 \%$ of subjects had fluorosis on both maxillary central incisors, but was severe in only 3 children. Amoxicillin use during the first year of life significantly increased the risk of fluorosis when compared with those who never used amoxicillin during this period. The association was strongest for use at 3-6 months of age; after adjustment for fluoride intake and history of AOM, the relative risk of fluorosis among amoxicillin-exposed children compared to those not exposed was 1.85 ( $\mathrm{RR}=1.85$; 95\% CI, 1.20-2.78). Fluoride intake was another significant predictor of subsequent fluorosis. No other antibiotics exposure was associated with fluorosis.

The explanation of the occurrence of enamel defects is unclear. It is difficult to establish with certainty a relationship between the maturation time of the tooth and the insult, there are several theories involving the enamel defects to different causes, but unfortunately these theories are not supported by scientific evidence. ${ }^{22}$

On the other hand in the first months of life, children undergo numerous episodes of infection and high fever after which make use of antibiotics. So it is possible that not only amoxicillin is the cause of these injuries, but we have to consider the synergistic effect with other risk factors. In the study of Whatling et al., 5 even if MIH was significantly more common among the subject for whom amoxicillin was the only antibiotic they had received $(\mathrm{P}=0.028)$, the authors conclude that this finding not provide firm evidence that amoxicillin is an etiological agent in this enamel defects. In fact children prescribed with antibiotics were usually ill, and it was not possible to determine whether the drug, or the disease, or both, or the combination with other risk factors were the cause of the enamel defect.

Although the Hong's study "was a well-designed, longitudinal epidemiological study, limitation must be acknowledged". 7 In fact study limitations include use of a convenience sample, relatively high socioeconomicus status, use of self-administred questionnaires without direct verification in which they are mentioned only those diseases associated with the use of antibiotics, so it was not possible to rebuild a patient's complete medical history, furthermore data on fevers, fever-reducing medication and exposure to all the potentially sources of fluoride were not collected. As also mentioned by the authors, there were incomplete questionnaire data for many individuals during some reporting periods and study dropout by some partecipants. Some authors ${ }^{2,3,23,24}$ have commented on the findings and limitations of the work of Hong, ${ }^{7}$ concluding that more research is needed to establish a real association between amoxicillin use and fluorosis. The findings of Hong7 
contrast with the findings of Arrow ${ }^{3}$, in fact the outcome of this study was that the type of childhood illness and type of medications were not statistically significant factors, so the use of amoxicillin was not associated with diffuse enamel defects. These results are in agreement with the study of Crombie et al.,2 where the intake of amoxicillin was not found to have an association with enamel defects. The authors also support that the data of the study of Hong7 were analysed on a per-year basis, the number for each factor assessed was not described and for this reason it was possible that very small sample sizes affected the results of the statistical analysis. Aldous, ${ }^{23}$ in his comment on the study of Hong et al., 7 criticized the decision to exclude questionable fluorosis cases from the study group, and reanalyzed the data provided by the authors including also this type of fluorosis. Although the results of Aldous et al. ${ }^{23}$ showed a persistent association between amoxicillin and fluorosis, the authors believed that this association was still doubtful because subjects in the study group took fluoride at the same time of amoxicillin, the role of fluoride in the genesis of fluorosis should not be excluded. Furthermore, according to the authors, even if an association was present, the clinical significance was questionable because they were mild fluorosis and so they had little functional implications. The skepticism shown by Aldous et al. ${ }^{23}$ was in agreement with that of Casamassimo, ${ }^{24}$ who argued that fluorosis is a disease that existed before the use of amoxicillin. So it is important to evaluate the role of fluoride and diseases as confounding factors; in fact, as noted by Hong et al.,7 users of amoxicillin also tended to have high intakes of fluoride, especially in tablets. Furthermore in the questionnaire of Hong et al.7, only diseases requiring the use of antibiotics were reported, leaving doubts about the possible role of high fever and various sources of fluoride intake in determining fluorosis. ${ }^{24}$

In agreement with results obtained by Hong ${ }^{7}$, Laisi ${ }^{20}$ argues that there was a correlation between the early use of amoxicillin and enamel defects. In this clinical study they examined 141 schoolchildren for $\mathrm{MIH}$, and from their medical files, recorded the use of antibiotics under the age of 4 yrs. The authors concluded that MIH was more common among those children who had amoxicillin during the first years of life. These results are in agreement with another study, 25 that suggested that the first years are critical for the development of enamel defects.

These results should be considered with caution because, although the authors state that parents completed a healthrelated questionnaire, childhood illness were not controlled for in the analysis. For this reason we are not able to assess if amoxicillin is to be connected to the MIH or to the fluoride intake, or to the disease for which this drug has been prescribed. ${ }^{21}$ In agreement with the studies mentioned above and the recent study of Phippis, ${ }^{21}$ there are insufficient data to state with certainty whether the amoxicillin or the disease for which this drug has been prescribed, or any other risk factors are the cause of the enamel defect.

A contribution of some interest is also the experimental study of Laisi et al. ${ }^{20}$ conducted on the mouse E18 teeth culture, founding that amoxicillin enhanced enamel formation and altered the pattern of amelogenesis interfering with mineralization. Furthermore amoxicillin had no effect on dentin thickness. The authors argued that amoxicillin induces earlier enamel formation and/or accelerates the accretion rate of the established enamel.

According to Phippis, ${ }^{21}$ even if the authors supposed that the early use of amoxicillin was among the causative factors of $\mathrm{MIH}$, it has to be considered that, in the experimental study, the solutions of amoxicillin added to the exposed explant were $100 \mu \mathrm{g} / \mathrm{mL}, 1 \mathrm{mg} / \mathrm{mL}, 2 \mathrm{mg} / \mathrm{mL}$ and $4 \mathrm{mg} / \mathrm{mL}$ but only $1 \mathrm{mg} / \mathrm{mL}$ or more concentrations were significative. So if one assumes that this model reflects the situation in humans, it is possible that amoxicillin interferes with ameloblast function and either advances the initiation of amelogenesis and/or accretion rate; however, the concentrations where alterations were noted were substantially higher than the optimal serum level in humans $(100 \mu \mathrm{g} / \mathrm{mL})$. So, according to Phippis, ${ }^{21}$ it can be assumed that there was no differences between unexposed controls and exposed explants at the concentration of $100 \mu \mathrm{g} / \mathrm{mL}$, suggesting that the therapeutic concentrations of amoxicillin in humans is not associated with enamel alterations in mice.

Furthermore Laisi et al. ${ }^{20}$ supposed that erythromycin is another putative cause of $\mathrm{MIH}$, even if, on this data, there was no scientific evidence and its role needs to be further studied.

Even in this case, the possible role of other risk factors cited in literature such as vaccination, chickenpox, high fever, prenatal intrauterine pressure, has not been verified. The authors assessed only the fluoride content of water and the additional fluoride in tablets.

This study, as the precedent, is a retrospective analysis based on a questionnaire, so it is subjected to confounding bias.

\section{Discussion}

The primary purpose of this work was to collect an update relative to the relationship between amoxicillin and Fluorosis. Even if the results of these study do not lead to recommendations to suspend the prescription of amoxicillin in the first years of age, they suggest that there could be a link between amoxicillin use during infancy and development of dental enamel defects of permanent teeth. According to the experimenatl study of Laisi et al.,20 at therapeutic concentrations amoxicillin in humans is not associated with enamel alterations, but in our opinion paediatricians must pay attention to the number of cycles of therapy in case of repeated treat- 
ments, and to the high cumulative doses of this drug, especially in the presence of other contributing factors. Should not be excluded that amoxicillin may act as epigenetic factor on genes that stimulated can promote the expression of dental fluorosis. The primary treatment for the resolution of upper respiratory tract infections and specially for AOM, involves the use of antibiotic, sometimes with differences from the type and duration of treatment, although in approximately $60 \%$ of cases, the etiology is viral. 18,26,27

A reduction of the excessive and inappropriate recourse to an antibiotic therapy could be necessary to avoid the possible onset of bacterial resistance and other side-effects, such as enamel defects. So it could be appropriate the evaluation of the age and of the repeated use and cumulative dose of amoxicillin, the presence of acute symptoms of illness such as fever, ear pain or respiratory symptoms and the otoscopic examination, taking into account the possibility of an occasionally substitution of the antibiotic used.

In general would be indicated to protect all children with 13 valent pneumococcal vaccine, meningococcal vaccine and to vaccinate all children at risk (chronic diseases affecting the respiratory system, congenital metabolic disease etc.) over the age of six months against seasonal influenza, according to the instruction of the Ministry of Health. This prophylactic treatment is desirable because it could produce a reduction of infectious disease and a lower consumption of antibiotics, especially Amoxicillin.

It is also important to remember that in cases of AOM the rate of spontaneous resolution is of $80 \%,{ }^{28}$ so it is necessary to reevaluate the use of antibiotics in children who experience this disorder.

Guidelines recommend using an approach of "watchful waiting" or "observation" as an alternative to treatment with antibiotics in selected children older than 6 months of age with AOM. 16,30-32

Moreover, guidelines emphasise the need for optimum treatment with analgesic drugs (mainly paracetamol and ibuprofen) as an adjunct for pain control. ${ }^{16}$ So it is essential that every health care professional who is involved with the prescription of drugs be fully aware of any resultant disorder that may arise as a side-effect. ${ }^{16,33}$

Furthermore, it must be considered the role of fluoride in the genesis of fluorosis. The availability of fluoride in the oral cavity, at therapeutic doses, increases the resistance of enamel to acid attack, reducing the solubility in acid of calcium ion content in enamel hydroxyapatite. This occurs through the replacement of calcium ions of hydroxyapatite to form fluorapatite.

Since the risk of fluorosis is dose-dependent, pratictioners should pay attention to prescribe systemic fluoride considering that children are exposed to multiple sources of fluoride, considering also the other factors causing fluorosis during the tooth development; thus, it is necessary to account the con- centration of fluoride in water and foods. (TABLE 1). Even if in literature few articles link the relationship between fluoride intake and dental fluorosis, ${ }^{34}$ the evidence suggests that 0.05 $0.07 \mathrm{mg}$ fluoride/kg body weight/day should be considered the safety threshold beyond that the risk of fluorosis increased.9,10 This value should be taken into account not only after weaning, but also in the preparation of infant formula when breast milk is not available. Unlike breast milk, in which fluoride concentration is approximately 0.02 parts per million (ppm), the fluoride levels in infant formula are determined by the industrial processes involved in preparing the infant formula and by the fluoride levels in the water used for reconstitution. 35

In fact, if the infant is fed with formula milk powder prepared with mineral water, the amount of milk to be taken within 24 hours is obtained during the first 4-6 months of life using this simple formula: infant weight in $\mathrm{kg}$ x 150-160 ml.

This means that an infant weighing $5 \mathrm{~kg}$ would take 750-800 $\mathrm{ml}$ of milk ( $5 \times 150-160 \mathrm{ml})$.

Therefore the threshold value for the development of fluorosis is greatly exceeded if water with high fluorine content is used (TABLE1). For this reason it is always advisable to know the fluoride content and other minerals dissolved in the mineral water for the preparation of milk formula.

In fact, according to Philippe et al. 35 the consumption of infant formula is associated with an increased risk of developing enamel fluorosis and, when fluoride concentration increased in the water supply, the risk of developing fluorosis associated with infant formula use increased.

There should be a consideration also regarding the use of topical fluorides. There is weak evidence that starting the use of fluoride toothpaste in children under 12 months of age may be associated with an increased risk of fluorosis, even if the fluoride level of toothpaste for children under 6 years of age is recommended to be lower than 1000 parts per million (ppm). ${ }^{36-38}$ Furthermore fluoride concentrations of $1000 \mathrm{ppm}$ was statistically significant in preventing caries. ${ }^{39}$ The works of Wong et al. and Rasines et al. also suggest the need of others trials to assess the effectiveness of different types of topical fluorides, even if may be unethical to propose RCT.36,37

\section{Conclusion}

Management of upper respiratory tract infections and specially pediatric AOM, common and usually self-limiting condition and often of viral aetiology, includes the observation strategy for selected and uncomplicated cases, older than 2 years of age, only when adequate follow-up can be ensured. Otherwise, an antibiotic treatment should be prescribed. Amoxicillin is the first-choice therapy but when symptoms persist or worsen, amoxicillin/clavulanate or cefpodoxime proxetil, or ceftriaxone are recommended. ${ }^{16,17}$ There are insuf- 
ficient data to support that amoxicillin causes enamel defects, however not considering the possible hypothetical side effects of this drug could still be wrong.

Even if an evidence is not been achieved, these studies suggest to consider this event, making use, where possible, of alternative treatments. Therefore, it is recommended that pediatricians consider a preventive approach to reduce bacterial complications in children at risk. Furthermore, for the treatment of $\mathrm{AOM}$, it is also recommended to adopt an approach of "watchful waiting" or "observation" and the use of analgesic drugs for pain control. 16,29-32

There is a need of further well-designed studies to assess the scientific evidence of the links between amoxicillin during infancy and the development of dental enamel defects of permanent teeth.

Probably with the introduction of Electronic Patient Record will be easier to trace many possible confounding factors, which today does not allow us to draw any definitive conclusion.

\section{Bibliografia}

1 Aoba T, Fejerskov O. Dental fluorosis: chemistry and biology. Crit Rev Oral Biol Med. 2002;13(2):155-70.

2 Crombie F, Manton D, Kilpatrick N. Aetiology of molar-incisor hypomineralization: a crtical review. Int $\mathrm{J}$ Paediatr Dent. 2009;19(2):73-83

3 Arrow P. Risk factors in the occurrence of enamel defects of the first permanent molars among schoolchildren in Western Australia. Community Dent Oral Epidemiol. 2009; 37(5):405-15.

4 Alaluusua S. Aetiology of Molar-Incisor Hypomineralisation: A systematic review. Eur Arch Paediatr Dent. 2010;11(2):53-58.

5 Whatling R, Fearne JM. Molar incisor hypomineralization: a study of aetiological factors in a group of UK children. Int J Paediatr Dent. 2008;18(3):155-62.

6 Beentjes VE, Weerheijm KL, Groen HJ. Factors involved in the aetiology of molar-incisor hypomineralisation $(\mathrm{MIH})$. Eur J Paediatr Dent. 2002;3(1):9-13.

7 Hong L, Levy SM, Warren JJ, Dawson DV, et al. Association of amoxicillin use during early childhood with developmental tooth enamel defects. Arch Pediatr Adolesc Med. 2005;159(10):943-48.

8 Berg J, Gerweck C, Hujoel PP, King R, et al. American Dental.Evidence-based clinical recommendations regarding fluoride intake from reconstituted infant formula and enamel fluorosis: a report of the American Dental Association Council on Scientific Affairs. J Am Dent Assoc. 2011;142(1):79-87.

9 Burt BA. The changing patterns of systemic fluoride intake. J Dent Res. 1992;71(5):1228-37.

10 Guha-Chowdhury N, Drummond BK, Smillie AC. Total fluoride intake in children aged 3 to 4 years—a longitudinal study. J Dent Res. 1996;75(7):1451-57.

11 DenBesten PK. Biological mechanisms of dental fluorosis relevant to the use of fluoride supplements. Community Dent Oral Epidemiol. 1999;27(1):41-47.
12 Farah RA, Monk BC, Swain MV, Drummond BK. Protein Content of Molar-Incisor Hypomineralisation Enamel. J Dent. 2010; 38(7):591-96.

13 Weerheijm KL, Jalevik B, Alaluusua S. Molar-incisor hypomineralisation. Caries Res. 2001;35(5):390-91.

14 Xie Z, Kilpatrick NM, Swain MV, Munroe PR, Hoffman M. Transmission electron microscope characterisation of molar-incisor-hypomineralisation. J Mater Sci Mater Med. 2008;19(10):3187-92.

15 Kaner D, Bernimoulin JP, Kleber BM, Friedmann A. Minimally invasive flap surgery and enamel matrix derivative in the treatment of localized aggressive periodontitis: case report. Int J Periodontics Restorative Dent. 2009;29(1):89-97.

16 Vergison A, Dagan R, Arguedas A, Bonhoeffer J, et al. Otits media and its consequences: beyond the earache. Lancet Infect Dis. 2010;10(3):195-203.

17 Bonsignori F, Chiappini E, De Martino M. The infections of the upper respiratory tract in children. Int J Immunopathol Pharmacol. 2010;23(1Suppl):16-19.

18 Klein JO. Is acute otitis media a treatable disease? N Engl J Med. 2011;364(2):168-69.

19 Hong L, Levy SM, Warren JJ, Bergus GR, et al. Primary tooth fluorosis and amoxicillin use during infancy. J Public Health Dent. 2004 Winter;64(1):38-44.

20 Laisi S, Ess A, Sahlberg C, Arvio P, et al. Amoxicillin may cause molar incisor hypomineralization. J Dent Res. 2009;88(2):132-16.

21 Phipps KR. No evidence to support the claim that amoxicillin causes molar-incisor hypomineralization. J Evid Based Dent Pract. 2010;10(2):112-14.

22 William V, Messer LB, Burrow MF. Molar incisor hypomineralization: review and recommendations for clinical management. Pediatr Dent. 2006;28(3):224-32.

23 Aldous. Amoxicillin use in infancy and enamel defects in permanent teeth. AAP Grand Rounds 2006;15:14-15.

24 Casamassimo PS. Amoxicillin and fluorosis: too soon to cap the medicine bottle? Arch Pediatr Adolesc Med. 2005;159(10):995-96.

25 Schour I, Massler M. The development of the human dentition. J Am Dent Assoc 1941; 28:1153-60.

26 Hoberman A, Paradise JL, Rockette HE, Shaikh N, et al. Treatment of acute otitis media in children under 2 years of age. $\mathrm{N}$ Engl J Med. 2011;364(2):105-15.

27 Tähtinen PA, Laine MK, Huovinen P, Jalava J, et al. A placebocontrolled trial of antimicrobial treatment for acute otitis media. $\mathrm{N}$ Engl J Med. 2011;364(2):116-26.

28 Spiro DM, Tay KY, Arnold DH, Dziura JD, et al. Wait-and-see prescription for the treatment of acute otitis media: a randomized controlled trial. JAMA. 2006;296(10):1235-41.

29 Leibovitz E. Acute otitis media in children aged less than 2 years: drug treatment issues. Paediatr Drugs. 2006;8(6):337-46.

30 Brunton S, Pichichero ME. Acute otitis media: influence of the PCV-7 vaccine on changes in the disease and its management. J Fam Pract. 2005;54(11):961-68.

31 McCormick DP, Chonmaitree T, Pittman C, Saeed K, et al. Non severe acute otitis media: a clinical trial comparing outcomes of watchful waiting versus immediate antibiotic treatment. Pediatrics. 2005;115(6):1455-65. 
32 Pappas DE, Owen Hendley J. A scholarly review of the evidence. Minerva Pediatr. 2003; 55(5):407-14.

33 Tredwin CJ, Scully C, Bagan-Sebastian JV. Drug induced disorders of teeth. J Dent Res. 2005;84(7):596-602.

34 Martins CC, Paiva SM, Lima-Arsati YB, Ramos-Jorge ML, et al. Prospective study of the association between fluoride intake and dental fluorosis in permanent teeth. Caries Res. 2008;42(2):125-33.

35 Hujoel PP, Zina LG, Moimaz SA, Cunha-Cruz J. Infant formula and esame fluorosis: a systematic review. J Am Dent Assoc. 2009;140(7):841-54.

36 Wong MC, Glenny AM, Tsang BW, Lo EC, Worthington HV,
Marinho VC. Topical fluoride as a cause of dental fluorosis in children. Cochrane Database Syst Rev. 2010 Jan 20;(1):CD007693.

37 Rasines G. Using a fluoridated supplement with a high fluoride concentration in children aged under 6 years may increase the risk of fluorosis. Evid Based Dent. 2010;11(1):8-9.

38 Wong MC, Clarkson J, Glenny AM, Lo EC, Marinho VC, et al. Cochrane reviews on the benefits/risks of fluoride toothpastes. J Dent Res. 2011;90(5):573-79.

39 Rasines G. Fluoride toothpaste prevents caries in children and adolescents at fluoride concentrations of 1000 ppm and above. Evid Based Dent. 2010;11(1):6-7.

\section{ERRATA CORRIGE. Volume 33, Numero 4, Luglio-Agosto 2011}

- Problemi di antisepsi nei neonati prematuri

Skin antisepsis in premature infants G. Agolini, G Faldella, E Janes, A Raitano, M Spinelli, M Vitali

A pag. 171:

Tabella 1a. Le percentuali di ipoclorito riportate come $0,6 \%$ vanno corrette in $0,06 \%$

A pag. 175:

1a colonna, paragrafo "conclusioni", riga 12. Le percentuali di ipoclorito riportate come $0,6 \%$ vanno corrette in $0,06 \%$

A pag. 172:

2a colonna, 6a riga. Le 100 ppm di NaDCC corrispondono allo 0,01\% 